\title{
Use of a polymeric sealant to reduce air leaks after lobectomy
}

\author{
Federico Venuta, MD, Daniele Diso, MD, Tiziano De Giacomo, MD, Marco Anile, MD, Erino A. Rendina, MD, \\ and Giorgio F. Coloni, MD, Rome, Italy
}

$\mathrm{A}$ ir leakage is a relatively frequent complication after lobectomy ${ }^{1}$; it can be expected in up to $15 \%$ of the patients, independently from the type of surgical approach (open or thoracoscopic). The risk increases when interlobar fissures are incomplete and in patients with emphysema; in nearly all series it contributes to increase the length of hospitalization and thus the costs.

Prolonged air leaks is defined as a leakage persisting 7 or more days. $^{2}$ Ideally, treatment begins with prevention: when fissures are incomplete, meticulous attention should be given to the anatomic planes of interlobar dissection. Several strategies can be employed to reduce the incidence of this complication ${ }^{3}$ : staplers and reinforcement materials could be used; a pleural tent or pneumoperitoneum could be performed if at the end of the operation the lung is not likely to reach the chest wall and fill the pleural space; also the use of surgical sealants and glues have been repeatedly proposed with encouraging results. ${ }^{4}$ However, none of these methods have definitively contributed to solve the problem and randomized studies are extremely rare.

The aim of the present study was to evaluate the role of Coseal (Baxter Healthcare, Deerfield, IL) (a polymeric sealant) to reduce postoperative air leaks and hospital stay.

\section{Clinical Summary}

Fifty consecutive patients undergoing standard pulmonary lobectomy for lung cancer and with incomplete or absent fissures that needed to be opened both anteriorly and posteriorly were prospectively enrolled in this study. The project was approved and partially supported by the University of Rome "La Sapienza." Patients with anatomically well-defined fissures were excluded as well as patients with lesions already treated with neoadjuvant chemotherapy or who previously underwent thoracic operations, patients with T3 tumors with chest wall involvement, and patients with extensive pleural adhesions. All interlobar fissures were completed with a GIA 75 or/and an EndoGia 45 stapler (Ethicon, Somerville, NJ). Patients were intraoperatively randomized into 2 groups: group I ( 25 patients; 15 men; mean age $61.3 \pm 12.6$ years) patients received Coseal over the newly designed fissure; group II (25

From the University of Rome "La Sapienza," Department of Thoracic Surgery, Rome, Italy.

Received for publication March 8, 2006; accepted for publication March 23, 2006.

Address for reprints: Federico Venuta, MD, Cattedra di Chirurgia Toracica, Policlinico Umberto I, University of Rome "La Sapienza," V.le del Policlinico, Rome 00100, Italy (E-mail: sofed@libero.it).

J Thorac Cardiovasc Surg 2006;132:422-3

$0022-5223 / \$ 32.00$

Copyright (C) 2006 by The American Association for Thoracic Surgery doi:10.1016/j.jtcvs.2006.03.047
TABLE 1. Pre-, intra-, and postoperative variables

\begin{tabular}{lrr}
\hline & Group I & Group II \\
\hline $\mathrm{FEV}_{1}$ & $2.6 \pm 0.7$ & $2.3 \pm 0.7$ \\
$\mathrm{PaO}_{2}$ & $87 \pm 10$ & $90 \pm 15$ \\
Upper lobectomy & $10(40 \%)$ & $15(60 \%)$ \\
Lower lobectomy & $12(48 \%)$ & $7(28 \%)$ \\
Middle lobectomy & $3(12 \%)$ & $3(12 \%)$ \\
Duration of drainage (d) & $5.6 \pm 3.5$ & $10 \pm 12$ \\
Hospitalization (d) & $8 \pm 3.7$ & $11.6 \pm 6.8$ \\
\hline
\end{tabular}

patients; 19 men; mean age $61.6 \pm 12.5$ years) patients were closed without any sealant.

For each patient we recorded age and gender, preoperative functional parameters, type of lobectomy, presence of air leakage during the first 5 days after the operation, duration of the air leaks, and duration of postoperative stay. Follow-up for morbidity and mortality lasted 1 month after the operation.

The differences in duration of air leaks were compared with the Yates corrected $\chi^{2}$ test; differences in forced expiratory volume in 1 second $\left(\mathrm{FEV}_{1}\right)$, duration of air leakage, chest tube drainage, and length hospitalization were assessed with the Student $t$ test.

\section{Results}

The preoperative functional parameters, type of lobectomy, and postoperative variables are reported in Table 1 . There were no statistically significant differences between the 2 groups for gender, age, functional variables, and type of surgical resection. Differences in terms of duration of drainage $(P=.03)$, hospital stay $(P=.009)$, and presence of air leakage during the first 5 days (day $1: P=.05$; day $2: P=.009$; day $3: P=.002$; day $4: P=.0005$; day 5: $P=.01$ ) were observed. A prolonged air leak (more than 7 days) was present in $2(8 \%)$ and $5(20 \%)$ patients, respectively, in groups I and II.

\section{Discussion}

Various methods have been proposed to close or seal lung parenchyma. Sealant materials need to be sufficiently strong and adherent to withstand pressures of 30 to $40 \mathrm{~cm}$ of water, but also elasticity once polymerized is an important issue to accomplish lung movements during respiration. They also need to be locally nonirritating, systematically nontoxic, without antigenicity, and bacteriostatic.

Many studies have reported the use of sealants and glues to reinforce the parenchymal suture line at risk for air leak, but no one has report on the use of Coseal. In our study Coseal seemed to reduce the duration of postoperative air leaks and hospitalization. It is easy to use and it did not induce any morbidity. However, although reduced in incidence, air leaks were still present in a small group of patients and in $2(8 \%)$ of them they persisted for 
more than 7 days, requiring a blood patch to definitively close. The use of this sealant in selected cases could contribute to reduce the incidence of this complication; if it occurs, the duration is certainly shorter. $^{5}$

\section{References}

1. Rice TW, Kirby TJ. Prolonged air leak. Chest Surg Clin N Am. 1992; 2:803-11.
2. Kirsh MM, Rotman H, Behrendt DM, Orringer MB, Sloan H. Complications of pulmonary resection. Ann Thorac Surg. 1975;20:215-36.

3. Venuta F, Rendina EA, De Giacomo T, et al. Technique to reduce air leaks after pulmonary lobectomy. Eur J Cardiothorac Surg. 1998;13: 361-4.

4. Wain JC, Kaiser LR, Johnston DW, et al. Trial of a novel synthetic sealant in preventing air leaks after lung resection. Ann Thorac Surg. 2001;71:1623-9.

5. Fleishner AG, Evans KG, Nelems B, Finley RJ. Effect of routine fibrin glue use on the duration of an air leak after lobectomy. Ann Thorac Surg. 1990;49:133-4.

\section{Extrapleural hematoma as a complication of spontaneous pneumothorax}

El Hassane Kabiri, MD, Adil Arsalane, MD, Abdelfettah Zidane, MD, and Fouad Atoini, MD, Rabat, Morocco

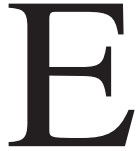
xtrapleural hematoma (EH) is rare. Only a few cases have been reported under different names: extrapleural, subpleural, or epipleural hematoma. It is potentially lethal because of bleeding risks and ventilatory consequences. ${ }^{1}$ We present a patient with an EH after spontaneous pneumothorax who successfully underwent operation.

\section{Clinical Summary}

A 23-year-old man was referred to our department for acute right-sided chest pain and dyspnea. The patient was in a stable hemodynamic state; his arterial pressure was $110 / 75 \mathrm{~mm} \mathrm{Hg}$, heart rate was 110 beats/min, oxygen saturation was $96 \%$, hematocrit value was $28 \%$, and hemoglobin value was $9.3 \mathrm{~g} / \mathrm{dL}$. Chest radiography showed an important basal pleural effusion, an apical pneumothorax, and a rounded opacity in the upper right side of the thorax with delineated convex borders suggesting an extrapleural lesion mimicking a benign tumor (Figure 1). Chest drainage removed $1600 \mathrm{~mL}$ of blood and revealed air leakage. Thoracic computed tomography scan (Figure 2) confirmed hemothorax and revealed a well-defined, hyperdense mass in the upper right side, measuring $4.5 \times 4.0 \mathrm{~cm}$. This mass was not surrounded after contrast injection. This finding was compatible with the diagnosis of hemopneumothorax complicating a pleural benign tumor such

\footnotetext{
From the Department of Thoracic Surgery, Mohamed V Military Teaching Hospital (Hôpital Militaire d'Instruction Mohammed V), Rabat, Morocco.

Received for publication Jan 23, 2006; accepted for publication March 23, 2006.

Address for reprints: El Hassane KABIRI, MD, Immeuble 29 Appt 7, Résidence Mes Ellil, Secteur 23, Riad 10100, Rabat, Morocco (E-mail: hassankabiri@yahoo.com)

J Thorac Cardiovasc Surg 2006;132:423-4

$0022-5223 / \$ 32.00$

Copyright $\odot 2006$ by The American Association for Thoracic Surgery doi:10.1016/j.jtcvs.2006.03.051
}

as a fibroma. Surgery was indicated both for examination of the thoracic mass and treatment of pneumothorax. Surgery was performed through a mini-posterolateral thoracot-

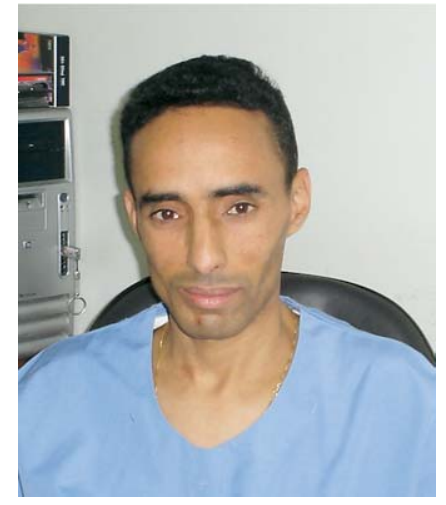

Dr Kabiri omy. A blood collection between the parietal pleura and the endothoracic facia was discovered. The hematoma was evacuated, and a pleural abrasion was performed. The postoperative course was uneventful. The chest tube was removed on day 3 . The pathologic study of a fragment of hematoma showed no abnormality.

\section{Discussion}

EH can be defined as the presence of blood in the extrapleural space between the parietal pleura and the endothoracic fascia.

The presence of blood between the lung parenchyma and the visceral pleural is impossible because of the lack of space between the lung and the visceral pleura. Many causes of EH have been suggested:

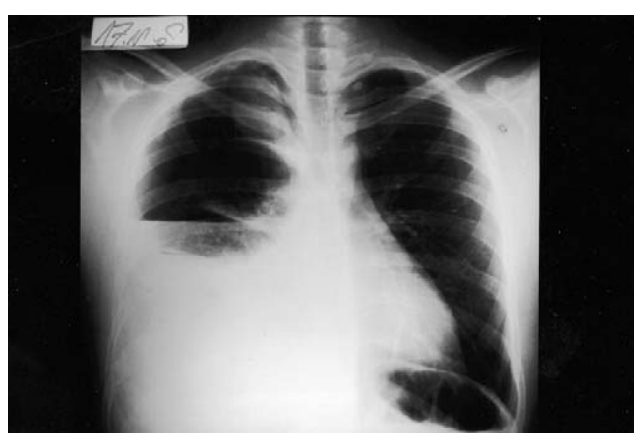

Figure 1. Chest x-ray film showing right pleural effusion, apical pneumothorax, and upper extrapleural mass. 